\title{
LANGUAGE AND ACADEMIC ACHIEVEMENT: PERSPECTIVES ON THE POTENTIAL ROLE OF INDIGENOUS AFRICAN LANGUAGES AS A LINGUA ACADEMICA
}

\author{
Mbulungeni Madiba \\ University of Cape Town
}

Although research literature abounds with studies that show the importance of language for academic achievement, the potential role of indigenous African languages in the educational sector in South Africa has not been adequately appraised or appreciated. Accordingly, ambivalence is still rife among parents, teachers, learners and government about the use of these languages for academic purposes. This ambivalence is evident from the existing national language education policies, school language policies, language curricula and language practices in schools. Thus, the purpose of this article is to discuss the perspectives on the potential role of indigenous African languages for academic purposes in South Africa. The focus is mainly on the use of these languages to provide a scaffold for academic language proficiency which is critical to academic success. To this end, a complementary language-use framework or model for using indigenous African languages to support the development of academic language in multilingual schools and universities is proposed.

\section{INTRODUCTION}

Although the issue of language and academic achievement has been the subject of much discussion and research in South Africa (Alexander, 2000, 2003; Heugh, 1995, 2011; Madiba, 2010a, 2010b; Setati, 2002; Webb et al., 2004), the potential role of indigenous African languages as linguae academica (academic languages) has not yet been adequately appraised or appreciated. Accordingly, parents, teachers, government and scholars have different perspectives on the use of these languages for academic purpose. Parents, for example, do not see the teaching of these languages at school as of any value for their children as they believe they have been fully mastered at home (Gough, 1999). The existing language-in-education policies, school language policies, language curricula and language practices in education also show government's ambivalence about the academic use of indigenous African languages in education. Although these perspectives on the use of indigenous African languages in education may be explained by citing politico-historical, economic and social factors, the more serious reason is academic ignorance, that is, ignorance of the importance of the mother tongue or multilingualism in scaffolding academic language and how this is done.

Accordingly, the aim of this article is to discuss the various perspectives on indigenous African languages as languages appropriated for academic purposes, with a view to exposing this academic ignorance and to propose a model for using these languages to bolster academic language proficiency. Although various perspectives exist on the role of African languages as academic languages, only two will be discussed in this article, namely, the nationalistic and 
the pragmatic perspectives. I will argue against these two perspectives since they are both based on a monolingual and separation-of-language approach (Garcia, 2009), which views African languages as singular discrete units. I thus propose a complementary language-use framework or model which involves the use of indigenous African languages or their varieties in complementarity to other languages such as English or its varieties to facilitate the development of academic language proficiency in multilingual schools and universities.

As noted, the article starts with a definition of academic language after which various perspectives on the potential role of indigenous African languages as academic languages in South Africa are discussed. This is followed by a brief overview of the reflection of these perspectives in the current National Curriculum Statements (NCSs) and the new Curriculum and Assessment Policy Statements (CAPS) and a proposed framework or model for the use of indigenous African languages in complementarity to other languages to support the development of academic language proficiency at both schooling or basic education and higher education levels. The focus of the proposed model is first on schooling level and later higher education.

\section{PERSPECTIVES ON INDIGENOUS AFRICAN LANGUAGES AS LINGUAE ACADEMICA}

\subsection{Defining the term academic language}

Academic language, also referred to in literature as school language, can be defined broadly as the language used in academic settings to help learners acquire and use knowledge (Snow \& Uccelli, 2009; Zwiers 2008). However, it can also be defined narrowly as 'the set of words, grammar and organisational strategies used to describe complex ideas, higher-order thinking processes and abstract concepts order' (Zwiers, 2008: 20). The first definition refers to usage or function, whereas the second focuses on structural or linguistic features of academic language. It is important to note, however, that academic language is difficult to define as it is complex and its terms of reference are wide. Thus, both structural features and function need to be considered in defining academic language. Structural or linguistic features include phonological, lexical, grammatical, sociolinguistics and discourse features (Scarcella, 2003). As no community can lay claim to any academic language as its mother tongue, it follows that any language in which high proficiency exists can be used to facilitate the development of academic language. In multilingual educational contexts, the development of academic language can be effectively facilitated through the use of more than one language.

However, in Africa as a whole, which is in fact home to over 2000 languages or a third of the world's languages (Heine \& Nurse, 2000), there seems to be no single indigenous African language that is used as a medium of instruction beyond primary education level in disciplines other than specific language courses (Prah, 2009). The languages of instruction in most African countries are the European languages, such as English, French and Portuguese. Africa, therefore stands out as one of the few developing countries where children are mainly educated through foreign languages. Many African scholars believe this to be among the main reasons for the high failure and drop-out rate of African learners in the course of their school careers (Alexander, 2000; Bamgbose, 2003; Heugh, 2011; Prah, 2009) and are therefore strongly in favour of the use of indigenous African languages as media of instruction, 
especially for the foundation phase of children's schooling career. Although there seems to be general agreement among African scholars on the potential role of indigenous African languages in education, their perspectives differ on the use of these languages as media of instruction beyond the primary level of schooling. These perspectives are divisible into nationalistic and the pragmatic types (Alidou \& Mazrui, 1999), premised on mutually exclusive theoretical arguments.

\subsection{The nationalistic perspective}

The nationalistic perspective considers indigenous African languages to be a panacea to educational problems facing African learners (Prah, 2009). Prah (2009: 159) has the following to say with regard to the role of indigenous African languages in education:

My argument is that African languages should be used for the entire educational system. So that Africans in their democratic majorities develop on the basis of their own histories, cultures and languages and also have confidence, self-affirmation and self-reliance in the production and reproduction of knowledge.

Although Prah's aspiration may be shared by many African scholars, this perspective has several shortcomings. First, it is unrealistic to propose the use of African languages for the entire educational system. Second, the nationalistic approach is criticised by several scholars because it is based on monolingual and separation-of-language ideology and as such tends to glorify the so-called standard indigenous African languages as discrete entities that can be enumerated and even named (Khubchandani, 2003; Makoni \& Pennycook, 2007). Makoni and Pennycook (2007) argued against the separation-of-language perspective and advocate the 'disinvention' of the so-called standard languages. Khubchandani (2003) argued for the need to revisit the conceptualisation of a 'home language' or 'mother tongue' in multilingual environments as in most of these contexts languages which learners identify as home languages or mother-tongue are not the actual languages they use at home. Therefore, a distinction should be made between languages in which the first speech acquired in infancy was expressed and languages used as markers of group or ethnic affiliation (Khubchandani, 2003). In South Africa, a good example is that of Northern Sotho, which has many dialects, yet the standard form used in school is mainly based on the Pedi dialect (Madiba and Mabiletja, 2008; Webb et al. 2004,). Thus, although Northern Sotho is recognised as a school language, this is not really the native speech for learners who are not speakers of the Pedi dialect (Madiba \& Mabiletja, 2008). Accordingly, if indigenous African languages are to be used as effective media of education, they should be seen as fluid and intermingling rather than as discrete entities.

The second shortcoming, which is often cited as one of the main obstacles to using indigenous African languages in education, is their low development status. As Bamgbose (2003:1) pointed out, 'whenever the question arises whether a policy concerning the use of an African language for learning and teaching is feasible or not', the argument of their inadequacy for academic purposes, especially in science, is made. Against this backdrop, there is an overemphasis of the need to intellectualise indigenous African languages before they can be used as media of instruction. The question here is 'What constitutes an intellectualised language?' An intellectualised language is defined by scholars such as Garvin (1973: 43) as a 
language that is equipped with 'more accurate and detailed means of expression, especially in the domains of modern life, that is, to say in the spheres of science and technology, of government and politics, of higher education, of contemporary culture, etc.' However, other scholars, such as Gonzalez (2002), supported a broader view, which includes aspects of language development such as a rich corpus of literature (imaginative and non-imaginative), including publications in academic fields, articles in newspapers and so on: the list is endless. According to Gonzalez, the intellectualised status of a language can be assessed by determining the extent of its use outside the classroom (e.g., in corridors, in canteens, on playing fields, and among the students when they socialise outside the immediate circle of the school) or when students are discussing academic topics in study groups or with faculty members in informal, academically focused conversations or in exchanges between faculty members and students (Gonzalez, 2002:16). All these and many others are useful indicators of whether or not a local language is in the process of intellectualisation or is expanding its domains and range of use.

In South Africa, the intellectualisation discourse is very prominent because indigenous African languages have not developed adequate academic registers in the different disciplines and therefore have to be intellectualised to render them suitable for use by teachers and learners for academic purposes (Alexander, 2003; Finlayson \& Madiba, 2002). Unfortunately, some language-intellectualisation approaches are informed by quasi-Darwinist evolution theories of language development, according to which all languages have to go through the same process of development that was followed by the so-called developed languages. In light of this perspective, it is said that indigenous African languages need to be intellectualised first before they can be used for educational purposes in the various domains of academic disciplines. However, this approach is flawed and may seriously delay the development of these languages for academic purposes, as languages develop through use. As Cooper (1989) noted, the form always follows the function, while the quasi-Darwinist approach goes against the common view. Putting the form before function is no different to putting the 'cart before the horse'.

Lastly, the form-first approach is inappropriate because for a language to be used in modern domains, for instance, academic purposes, as in the context under review, it requires not only word-lists or terminology glossaries but registers too. As Schiffman (1992) observed, registers are not developed in isolation from the language or translated from another language; instead, they are developed through language use and thus are developed primarily by a community of language users employing them interactively to solve particular communication problems or to perform particular tasks. Academic registers in African languages cannot be developed by bureaucrats or outsiders to the register. A good contemporary example of this is the evolution and development of a register for computer science. The English version of this register has developed along with the evolution and development of computing hardware, software, and computer science generally (Schiffman, 1992).

\subsection{The pragmatic perspective}

The advocates of the pragmatic perspective maintain that the determination of the use of any language in education should be based only on pragmatic considerations. As Alidou and Mazrui (1999) noted, many adherents of this perspective are not necessarily opposed to the centralisation of African languages, but they would see no need to use these languages in 
education as foreign languages such as English provide a more pragmatic choice (Alidou \& Mazrui, 1999). In South Africa, scholars associated with this perspective include Ezekiel Mphahlele, who regarded the use of colonial languages as a pragmatic choice because of the plurality of indigenous languages in most African countries which makes it difficult to promote nation-building (Mphahlele, 2004: 134). Furthermore, Mphahlele (2004) contended that indigenous languages are relatively underdeveloped, compared to colonial languages such as French, Portuguese and English, which are already elevated to the position of working tools, 'in a manner of speaking', tools used in a 'variety of idiomatic formations and levels of intensity according to social strata' (Mphahlele, 2004: 133). According to him, although African language speakers will gradually learn how to deal with these and other modern concepts, they will require more than two decades 'to build up indigenous vocabularies that will contain concepts not native to the African soil, but which are indispensable for discourse in modern life' (Mphahlele, 2004: 133).

However, just like the nationalistic perspective, the pragmatic perspective, too, has several shortcomings. First, this perspective fails to recognise that although colonial languages like English are unassailable, they are unattainable to the majority of the population (Alexander, 2000). Research shows that despite many years of colonialism in Africa, the spread of colonial languages has been very slow, and in most countries, their use continues to be restricted to the few elite persons who have access to education at a sufficiently advanced level. Thus, these languages, though dominant, continue to be accessible to the small group that use them to promote elite closure, according to which they appropriate education and economic privileges to themselves and exclude the poor or working class people. In South Africa, most of the children of the elite attend ex-Model C schools or private schools that use English as a medium of instruction from the first grade. Whereas the use of English as a medium of instruction does not seem to be a barrier to learning in these ex-Model-C schools, especially the upper class ex-Model-C schools (i.e., schools historically reserved for whites), which are well resourced and have good teachers and a relatively high racial mix, in lower class ex-Model-C and poor rural schools, the use of English as the only medium of instruction has devastating consequences (Howie, 2005a; Jordaan, 2011).

\section{TOWARDS A MULTILINGUAL MODEL FOR USING INDIGENOUS AFRICAN LANGUAGES FOR ACADEMIC PURPOSE}

It is clear from the foregoing that neither the pragmatic nor the nationalistic approach is conducive to effective academic proficiency in multilingual schools and higher education institutions as both are based on a monoglossic ideological approach to language use in education (Canagarajah, 2006; Garcia, 2009). Canagarajah (2006:598) criticised a monolingual approach to the use of indigenous languages as it ignores the reality of multilingualism demanded by globalisation and also segregates students who are speakers of these languages into what he refers to as 'vernacular speech ghettos'. Thus, it is understandable why scholars such as Garcia (2009) recommended a heteroglossic or translanguaging approach which promotes the simultaneous use of students' linguistic repertoires to assist in the development of academic language proficiency. This approach provides a better alternative to promote the use of indigenous African languages as academic languages in multilingual environments. However, the implementation of this model in South Africa seems to be constrained by existing language-in-education policies and curriculum 
frameworks, that is, the National Curriculum Statements (NCSs) and the new Curriculum and Assessment Policy Statements (CAPs) that seem to promote a monolingual and monoglossic ideology. The new Language-in-Education Policy adopted by government in 1997 (Department of Education, 1997) promotes additive bilingualism/multilingualism, that is, the maintenance of home language and the learning of at least one additional language. The policy provides guidelines on the teaching of indigenous African languages or home languages as subjects of study in their own right and as media of instruction. In terms of this policy, home languages, especially indigenous African languages, may be studied as subjects up to Grade 12. The policy requires that these languages be used as media of instruction for at least three years, after which scholars switch to an additional language which can be either English or Afrikaans. However, according to the South African Schools Act (Act of 1996), the school governing bodies have the power to decide which language should be used as the tuition medium in their schools, with the result that in some schools English is used as the only medium of instruction from Grade 1 . Where additive bilingualism is being implemented, research shows that it is not being done correctly (Heugh, 2011: 148). The implementation of the curriculum, it appears, is promoting early-exit bilingualism rather than additive or late-exit bilingualism, which is conducive to the development of academic language proficiency. At present, about 78\% of learners switch to English in Grade 4 (Heugh, 2011: 153). Accordingly, only an insignificant minority of English and Afrikaans students enjoy the benefits of monolingual mother-tongue education throughout their secondary and tertiary educational careers.

The early exit to English destabilises the development of academic language proficiency among the learners who have indigenous African languages as home languages. These students are transitioned to English before developing strong foundational academic language in their home language, and also, which is matter of concern, English has been included as the first additional language for only three years. As a result, learners move to English-medium tuition with a vocabulary of not more than 500 words, compared to native English learners with 7000 words at the same level of schooling (Heugh, 2011). This is not surprising as second language teaching is never aimed at preparing learners to use it as medium of instruction (Heugh, 2011: 142).

Given the foregoing, it can be argued that the current language curriculum merely facilitates transition from mother tongue to English without promoting transfer of cognitive academic language competences across languages and grades. In fact, as already mentioned, the curriculum does not recognise academic language as a distinct register that can be explicitly taught and transferred across languages and grades. As the curriculum is based on the OBE (the outcomes-based education) approach, its main focus is on proven skills acquisition rather than on academic language competences. A study by Van Rooyen and Jordaan (2009), for example, established that aspects of academic language such as vocabulary (concepts) and complex sentence comprehension are not always recognised and developed within the educational system. In a study by Van der Walt (2009) on code switching, she also noted curriculum ambivalence with regard to the use of this academic language aspect by teachers in dealing with language problems in class.

It is important to note that even in dealing with academic literacy the NCS leaves much to be desired. As Macdonald (2008) remarked, the new curriculum has completely marginalised academic literacy, particularly at Foundation Phase. In some instances, there seems to be a 
theoretical confusion in these curriculum documents on how some aspects of academic literacy should be taught. The old NCS, for example, promoted a whole-language teaching approach to literacy development, which was based on Western theories, and the new CAPSs have now reverted to a phonics approach and are very prescriptive about its use in schools. As literacy research shows (Christie, 2005), it is not question of either one or the other of these approaches as they can be used creatively together to develop academic literacy.

Another problem with the NCSs and the new CAPSs is that they are based on a monolingual and separation-of-language approach. The problem with this approach is that languages are taught or used separately from each other. The use of this approach in multilingual contexts is contrary to the educational theories of scholars such as Cummins (1979, 2000), who maintained that although languages may appear to be different on the surface, they have a common underlying storage. Thus, there is cross-linguistic influence, resulting in what Cummins (1984: 4) referred to as 'common underlying proficiency' (CUP). The use of each language contributes to this storage, with the result that languages are interdependent. Although, according to Cummins (2000), at least five to seven years are required to develop academic language proficiency to an adequate level, this period could be shortened with direct academic language instruction, with learners given enough support and exposure to the target language(s) (Scarcella, 2003).

The last problem with the NCS and the new CAPS regarding the use of indigenous African languages to facilitate academic language proficiency is that both were based on the English curriculum. The NSC and CAPS were originally written in English and then translated into the other languages (Murray, 2012). Whereas this approach is commendable since it establishes some form of standardisation, it runs the risk of overlooking certain aspects of African languages which are essential for the purposes of facilitating the development of academic language registers in these languages. For example, literary artifacts such as folktales, praise poems and songs, which are rich sources of specialised discourse or registers in these languages, are completely marginalised in the curriculum. Gough (1999: 171) has the following to say in this regard:

Amongst the Xhosa, for instance, traditional examples of secondary discourse types include rhetoric employed in various ceremonies like releasing the widow, opening a homestead, traditional legal discourse, in praise poetry or even a folktale.

Given the lack of clear frameworks or a model to facilitate the development and use of academic language in the South African education sector, with particular reference to multilingual schools, a complementary language use model is proposed to fill the gap (Dua, 1994; Madiba, 2004, 2010a). This model is based on the complementarity principle (Grosjean, 2008: 23), which requires the simultaneous use of African languages in tandem or complementarity with English or any other language as a medium for academic language development. This principle is in line with how bi-/multilinguals use their linguistic repertoires in daily life. Grosjean (2008: 23) contended that 'Bilinguals usually acquire and use their languages for different purposes, in different domains of life, with different people.' This model is characterised by language complementarities: between dialects and standard language, between home language and school language (academic language), between everyday (informal) and scientific (formal) language, and between conversational language 
and academic language.

Research has established that in multilingual schools, plurilingual teachers and learners shuttle between their first languages or language varieties and English, which is mostly used as the language of learning and teaching (Canagarajah, 2006, Balfour, 2005, Madiba \& Mabiletja, 2008, Plüddemann, 2011, Setati, 2002, Van der Walt \& Ruiters, 2011). The shift or complementarity between different languages or varieties may range from $1 \%$ to $99 \%$ depending on linguistic, sociocultural and political factors. Canagarajah (2006:589) described this kind of pedagogy as the 'pedagogy of shuttling between languages'. Balfour (2005:77) regarded this type of pedagogy as 'shifting pedagogy'. In South Africa, this tendency to shuttle between languages has been noted in several studies, particularly those carried out in urban schools (Madiba \& Mabiletja, 2008, Plüddemann, 2011, Setati, 2002, Van der Walt \& Ruiters, 2011). These studies clearly show that monolingual teaching and learning is no longer feasible in peri-urban schools, given the extent to which home languages are mixed with English. Thus, Plüddemann (2011:11) concluded that 'in most urban contexts in South Africa today, a monolingual orientation that insists on a strict use of the prestige or standard variety would be almost as alienating to learners as an English-only approach.'

The advantage of the proposed model is that it allows the simultaneous use of both indigenous African languages and English. Furthermore, this model shifts the focus away from viewing languages as discrete entities to viewing them as fluid and intermingling. Studies on code switching convincingly show how the intermingling of languages or dialects can be effective in developing students' academic language proficiency in the command of the language itself and across the curriculum (Van der Walt \& Ruiters, 2011). Several other studies show the effectiveness of using languages complementarily to facilitate aspects of academic language proficiency, such as concept literacy (Madiba, 2010b), high-order thinking skills (Cummins, 2000), multilingual writing (Canagarajah, 2009), and translanguaging (Creese \& Blackledge, 2011: Garcia, 2009: Plüddermann, 2011).

The following extract clearly illustrates how languages may be used in complementarity to facilitate the growth of concept literacy. The extract is taken from an Economics multilingual concept literacy tutorial exercise presented for Tshivenda students, selected from the first-year Economics course, forming part of the Academic Development Programme. Only students who have studied an African language as home language in Grade 12 were selected. These students participated in the tutorial voluntarily as it was only a pilot study. Students were allowed to use both English and their home language in the tutorial discussions. The tutorial, from which this extract was taken, focused on the concept of deficit. Seven students participated in this tutorial, which was facilitated by a post-graduate Tshivenda speaking tutor. At the beginning of the tutorial, students were requested to discuss the concept in English and then in Tshivenda. The aim of the tutorial discussion was to deepen participants' understanding of the concept. The following are the transcripts of the multilingual tutorial facilitated by a Tshivenda tutor and the author, who also speaks Tshivenda. Each student was asked to present his or her definition(s) of the concept of deficit to the rest of the group.

1. STUDENT 1: It is a shortage

2. TUTOR: No i talutshedza nga only one word

$<$ You explained it by only one word>

3. STUDENT 1: Ndi a balelwa actually u tou li dzudzanya lothe lo fhelela, but I know uri ri 
tshi khou ita surplus na [inaudible], hu tou nga hu vha hu na shortage ya zwinwe zwithu, hu khou dimandiwa hu si na zwine zwa khou sapulaiwa.

$<$ I am unable to actually describe it fully, but I know that when there is surplus and [inaudible], it seems we are dealing with shortage of things, there is a demand without supply>

4. STUDENT 2: Nne ndo ri deficit is a point when a loss has been made, especially in situation where expenses exceed income.

$<$ I say deficit is a point when a loss has been made, especially in situation where expenses exceed income.>

5. TUTOR: As is budget, because heyo ndi profit. Ndi profit or loss $<$ As is budget, because that is profit. It is profit or loss>

6. STUDENT 3: This is when you have used more than the budgeted amount.

7. STUDENT 4: Ok, it is the same because nne na nne ndi zwi sedza in terms of accounting, since I did accounting at school. If expenses $d z i$ tshi excee- $d a$ income, it is a loss. This is why I say deficit is a loss. This is you have used more than the budgeted amount.

$<\mathrm{Ok}$, it is the same because I also view it in terms of accounting, since I did accounting at school. If expenses do exceed income, it is a loss. Thus why I say deficit is a loss. This is when you have used more than the budgeted amount.>

8. TUTOR: Ndi loss if arali a khomphera expenses ndi loss arali a khou $i$ amba in terms of accounting, habe hafho u khou $i$ amba in terms of accounting.

$<$ It is loss if you compare expenses, it is loss if you are discussing it in terms of accounting, here you are discussing it in terms of accounting.>

9. STUDENT 4: A thi i pfesesi kha economics, ndi i pfesesa kha accounting.

$<$ I don't understand it in terms of economics, I understand it in terms of accounting>

10. STUDENT 5: Nne ndo nwala uri deficit is when the business is running a loss.

$<$ I wrote that deficit is when the business is running a loss. $>$

11. TUTOR: Again, no fokhasa more kha accounting, ne.

<Again, you have focused more on accounting, is indeed?>

The extract shows that students were using their home language, which is Tshivenda, in complementarity with English. However, it is important to also observe that their main focus was on meaning making or discourse rather than on form. Students drew from their linguistic repertoires using translanguaging to express themselves, and their discourse is couched in an economics register. In the extract provided here, Tshivenda was used as the matrix or the framing language and loan words from English were used with or without modification. Despite this mixture of languages or translanguaging, the definitions and the translation equivalents given by the students at the end of the tutorial clearly demonstrate their development of deeper understanding of the concept that was under discussion.

\section{CONCLUSION}

The aim of this article was to discuss perspectives on the role of indigenous African languages as academic languages. The focus was mainly on the use of these languages to provide a scaffold for devepoping academic language proficiency, which is critical to academic success. The pragmatic and nationalistic perspectives were discussed and duly rejected in favour of the 
principle of complementary language use which allows students to use English and indigenous African languages as media of learning. As South Africa is a multilingual country, indigenous African languages need to be used in conjunction with other languages to facilitate the development of academic language and academic literacy skills in general. As Robsinson (1996, cited in Hameso, 1997: 1) contended, 'the use of African languages in complementary and equitable fashion alongside other languages will be part of the full development of Africa's own genius and of the continent's search for its own path of development.'

The advantage of the proposed model is that it challenges the existing purist, insular, nationalistic attitudes towards indigenous African languages or standard languages as discrete entities that can be taught in isolation and used separately from each other; instead it proposes the view that in multilingual contexts such as South Africa these languages need to be viewed as fluid and should be used simultaneously in complementarity to other languages such as English to develop academic language proficiency.

\section{REFERENCES}

ALEXANDER, N. 2000. English unassailable but unattainable. The dilemma of language policy in South African education. PRAESA Occasional papers no.3. Cape Town, RSA: PRAESA.

ALEXANDER, N. 2003. The African Renaissance and the use of African languages in tertiary education. PRAESA Occasional Papers No 13. Cape Town, RSA: PRAESA.

ALIDOU, O \& A. MAZRUI. 1999. The language of Africa-centred knowledge in South Africa: Universalism, relativism and dependency. In Palmberg, M., National identity and democracy in Africa. Uppsala, Sweden: The Nordic Africa Institute/Cape Town, RSA: Mayibuye Centre of the University of the Western Cape and the Human Sciences Research Council. 101-118.

BALFOUR, R. 2005. Transforming a language curriculum: Shifting pedagogy for meaningful learning. Perspectives in Education, 23(1):77-87.

BAMGBOSE, A. 2000. International Association for World Englishes (IAWE) and World Englishes: Which way forward? In Smith, L.E. \& M.L. Forman (Eds.), World Englishes 2000 Honolulu, Hawai'i: University of Hawai'i Press: 204-208.

BAMGBOSE, A. 2003. Intellectualization of African languages: The Nigerian Experience. Workshop on Intellectuaization of African languages, PRAESA, University of Cape Town, 7-12 July 2003.

CANAGARAJAH, A S. 2006. Toward a writing pedagogy of shuttling between languages: Learning from multilingual writers. College English, 68(6):598-604.

COOPER, R. 1989. Language change and social change. Cambridge, UK: Cambridge University Press.

CREESE, A. \& BLACKLEDGE, A.2011. Ideologies and interactions in multilingual education: What can an ecological approach tell us about bilingual pedagogy? In C. Hélot, C. \& M.O. Laoire (Eds.). Language policy for the multilingual classroom. Bristol, UK: Multilingual Matters. 
CHRISTIE, F. 2005. Language education in the primary years. Sydney, Aus: University of New South Wales Press.

CUMMINS, J. 1979. Linguistic interdependence and the educational development of bilingual children. Review of Educational Research, 49(2):222-251.

CUMMINS, J. 1984. Wanted: A theoretical framework for relating language proficiency to academic achievement among bilingual students. In Rivera, C.(Ed), Language Proficiency and Academic Achievement. Clevedon, UK: Multilingual Matters.

CUMMINS, J. 2000. Language, power and pedagogy: Bilingual children in the crossfire. Clevedon, UK: Multilingual Matters.

DUA, H. 1994. Hegemony of English. Mysore, India:Yashoda.

FINLAYSON, R. \& MADIBA, M. 2002. The Intellectualisation of the Indigenous Languages of South Africa: Challenges and Prospects. Current Issues in Language Planning 3(1): 40-61.

GARCIA, O. 2009. Bilingual education in the $21^{\text {st }}$ century: A global perspective. Chichester, UK: Wiley-Blackwell.

GARVIN, PL. 1973. Some comments on language planning. In Rubin, J. \& R. Shuy (Eds.), Language planning: Current issues and research. Washington, DC: Georgetown University.

GONZALEZ, A. 2002. Language planning and intellectualization. Current Issues in Language Planning, 3(1):5-27.

GOUGH, D. 1999. African languages: discourse, concepts, education and other challenges. In Prah, KK (Ed), Knowledge in black and white. The impact of apartheid on the production and reproduction of knowledge. CapeTown, RSA: CASAS.

GROSJEAN, F. 2008. Studying bilinguals. Oxford, UK: Oxford University Press.

HAMESO, S. 1997. The language of education in Africa: The key issues. Language, Culture and Curriculum, 10(1):1-13.

HEINE, B \& D NURSE (Eds.). 2000. African languages: An introduction. Cambridge, UK: Cambridge University Press.

HEUGH, K. 1995. The multilingual school: Modified dual medium. In Heugh, K., A. Siegrühn \& P. Plüddemann (Eds.), Multilingual Education for South Africa. Johannesburg, RSA: Heinemann.

HEUGH, K. 2011. Theory and practice - language education models in Africa: Research, design, decision-making and outcomes. In Oune, A. \& C. Glanz. Optimizing learning, education and publishing in Africa: The language factor. A review and analysis of theory and practice in mother-tongue and bilingual education in sub-Saharan Africa. Tunis Belvedere: UNESCO, UNESCO Institute for Lifelong Learning, Association for Development of Education in Africa. 105-176.

HOWIE, S. 2005a. System-level evaluation: Language and other background factors affecting mathematics achievement. Prospects, 64(1):119-157. 
HOWIE, S. 2005b. Contextual factors in the school and classroom level related to pupils' performance in mathematics in South Africa. Educational Research and Development, 11(2):123-140.

JORDAAN, H. 2011. Delving into the development of academic language by foundation phase English language learners. Unpublished doctoral thesis, University of the Witwatersrand, Johannesburg, RSA.

KHUBCHANDANI, LM. 2003. Defining mother-tongue education in plurilingual contexts. Language Policy, 2:239-254.

MACDONALD, C.A. 2008. Are the children still swimming up the waterfall? A look at literacy development in the new curriculum. Language Matters, 33(1):111-141.

MADIBA, MR. 2004. 'Treading where angels fear most'-the South African Government policy on higher education and its implications. Alternation. 11(2):26-43.

MADIBA, M. 2010a. Towards multilingual higher education in South Africa: The university of Cape Town's experience. Language Learning Journal, 38(3):327-346.

MADIBA, M. 2010b. Fast-tracking concept learning to English additional language (EAL) students through corpus-based multilingual glossaries. Alternation, 17(1):225-248.

MADIBA, M. \& MABILETJA, M. 2008. An valuation of the implementation of the new Languagein-Education Policy (LiEP) in selected secondary schools of Limpopo Province. Language Matters, 39 (2):204-229.

MAKONI, S \& A PENNYCOOK. 2007. Disinventing and reconstituting languages (Bilingual education and bilingualism). Clevedon, UK: Multilingual Matters.

MEYER, JHF \& R LAND. 2006. Overcoming barriers to student understanding. Threshold concepts and troublesome knowledge. London, UK: Routledge.

MPHAHLELE, E. 2004. Es'kia continued. Literary appreciation, education, African humanism and culture, and social consciousness. Johannesburg, RSA: Stainbank \& Associates.

MURRAY, S. 2012. The standards of the National Senior Certificate Home Languages Examinations: A comparison of South African official languages. Pretoria, RSA: Umalusi.

PRAH, KK. 2009. The language of instruction in Africa. The language of instruction conundrum in Africa. In Brock-Utne, B \& G Garbo (Eds.), Language and power. The implications of peace and development. Dar es Salaam, Tanzania: Mkuki na Nyota.

PLÜDDEMANN, P. 2011. Crossing new frontiers with the translanguaging wagon. LEAPnews, 29:10-11.

SCARCELLA, R. 2003. Academic English: A conceptual framework. Santa Barbara, CA: Linguistic Minority Research Institute.

SCHIFFMAN, HF. 1992. 'Resisting arrest' in status planning: Structural and covert impediments to status change. Language \& Communication 12(1) 1-15.

SETATI, M. 2002. Researching mathematics education and language in multilingual South Africa. The Mathematics Educator, 12(2):6-20. 
SNOW, CE \& P UCCELLI. 2009. The challenge of academic language. In Olson, DR. \& N. Torrance (eds.). The Cambridge handbook of literacy. New York, NY: Cambridge University Press.

THESEN, L \& E VAN PLETZEN. 2006. Academic Literacy and Languages of Change.. London, UK: Continuum.

VAN DER WALT, C. 2009. The functions of code switching in English language learning classes. Per Linguam, 25(1):30 - 43.

VAN DER WALT, C \& J RUITERS. 2011. Every teacher a language teacher? Developing awareness of multilingualism in teacher education. Journal for Language Teaching, 45(2):84-98.

VAN ROOYEN, D \& N. JORDAAN. 2009. An aspect of language for academic purposes in secondary education: Complex sentence comprehension by learners in an integrated Gauteng school. South African Journal of Education, 29:271-287.

WEBB, VB LEPOTA \& RM RAMAGOSI. 2004. Using Northern Sotho as a medium of instruction in vocational training. Trends in linguistics: Studies and monographs. 159: 119-146.

\section{BIOGRAPHICAL NOTE:}

Mbulungeni Madiba is an associate professor and co-ordinator of the Multilingualism Education Project in the Centre for Higher Education Development at the University of Cape Town. He is also the Mandela Fellow at Harvard University. His current research interests include language planning and policy, multilingual education, corpus linguistics, terminology and terminography.

Email: mbulungeni.madiba@uct.ac.za 